\title{
PENGARUH PENERAPAN UNDANG-UNDANG KEPERAWATAN NO. 38 TAHUN 2014 TERHADAP KINERJA PERAWAT DI RUMAH SAKIT TK.IV ISKANDAR MUDA 07.01 LHOKSEUMAWE
}

\author{
Anda Syahputra, Asrul Fahmi \\ Program Studi D3 Keperawatan, Akper Pemkab Aceh Utara \\ E-mail : syahanda60@gmail.com \\ Program Studi D3 Keperawatan, Akper TK.IV Iskandar Muda 07.01 Lhokseumawe
}

\begin{abstract}
The research was carried out at TK. IV Iskandar Muda 07.01 Hospital Lhokseumawe. The research objective was to influence work motivation, leadership, work facilities, training and service reward with nurses performance in TK. IV IM 07.01 Hospital Lhokseumawe. The method of research was a quantitative research. Data obtained by asking the questionnaire to 75 respondents. The results showed work motivation, leadership, work facilities, training and service reward a positive and significant with nurse performance at TK. IV IM 07.01 Hospital Lhokseumawe. Hypothesis testing using the $\mathrm{F}$ test with a value of $\mathrm{F}$-count $=13.054$ with a significance of $0,000<0.05$. Variables in work motivation, leadership, work facilities, training and service reward are related to nurse performance. While the F-table with a significance level of $0.05(5 \%)$ was obtained at 2,500. Thus the results of the F test show the value of F-count> F-table that is 13.054> 2,500. This research show that there are influence between work motivation, leadership, training and service reward with nurse performance.
\end{abstract}

Keywords : Service Rewards, Leadership, Nurse Performance, Work Motivation, Training

\begin{abstract}
Abstrak
Penelitian ini dilakukan di Rumah Sakit TK.IV Iskadar Muda 07.01 Lhokseumawe. Penelitian ini bertujuan untuk mengetahui pengaruh motivasi kerja, kepemimpinan, fasilitas kerja, pelatihan dan imbalan jasa terhadap kinerja perawat pada Rumah Sakit TK.IV IM 07.01 Lhokseumawe. Metode penelitian yang digunakan adalah penelitian kuantitatif. Data diperoleh dengan menyebarkan kuesioner kepada 75 responden. Hasil Penelitian menunjukkan bahwa motivasi kerja, kepemimpinan, fasilitas kerja, pelatihan dan imbalan jasa berpengaruh positif dan signifikan terhadap kinerja perawat Rumah Sakit TK.IV IM 07.01 Lhokseumawe. Pengujian hipotesis menggunakan uji $F$ dengan nilai $F_{\text {hitung }}=13,054$ dengan signifikansi sebesar $0,000<0,05$. menunjukkan bahwa secara bersama-sama variabel motivasi kerja, kepemimpinan, pelatihan dan imbalan jasa mempunyai pengaruh terhadap kinerja perawat. Sedangkan nilai $\mathrm{F}_{\text {tabel }}$ dengan tingkat sigifikansi 0,05 (5\%) diperoleh sebesar 2,500. Dengan demikian hasil uji F menunjukkan bahwa nilai $\mathrm{F}_{\text {hitung }}>\mathrm{F}_{\text {tabel }}$ yaitu $13.054>2,500$. Hasil analisis ini dapat dijelaskan bahwa secara simultan motivasi kerja, kepemimpinan, pelatihan dan imbalan jasa berpengaruh signifikan terhadap kinerja perawat.
\end{abstract}

Kata Kunci : Imbalan Jasa, Kepemimpinan, Kinerja Perawat, Motivasi kerja, Pelatihan

\section{PENDAHULUAN}

Perawat merupakan aspek penting dalam pembangunan kesehatan. Perawat merupakan salah satu tenaga kesehatan, bahkan dalam penyelenggaraan pelayanan kesehatan tenaga perawat merupakan tenaga kesehatan terbesar yang dalam kesehariannya selalu berhubungan langsung dengan pasien dan tenaga kesehatan lainnya. Perawat merupakan salah satu profesi tenaga 
kesehatan yang memberikan pelayanan kesehatan langsung baik kepada individu, keluarga dan masyarakat. Kehadirannya adalah mengupayakan agar pasien mendapatkan kesembuhan atas masalah kesehatan yang diderita oleh pasien. Pelayanan kesehatan dan keperawatan yang dimaksud adalah bentuk implementasi praktik keperawatan yang ditujukan kepada pasien - klien baik kepada individu keluarga dan masyarakat dengan tujuan upaya peningkatan kesehatan dan kesejahteraan guna mempertahankan dan memelihara kesehatan serta menyembuhkan dari sakit, dengan kata lain upaya praktik keperawatan berupa promotif preventif, kuratif dan rehabilitasi (Prapuspa, 2013).

Lahirnya Undang - Undang Nomor

38 Tahun 2014 tentang Keperawatan menandakan bahwa para perawat telah mendapatkan jaminan, antara lain dalam hal peningkatan mutu perawat, peningkatan mutu pelayanan keperawatan; perlindungan dan kepastian hukum serta peningkatan derajat kesehatan masyarakat. Undang-undang Keperawatan (UUK) merupakan dasar hukum praktek keperawatan. Isi UUK harus diketahui oleh profesi dan calon profesi perawat (mahasiswa). Hal ini dikarenakan, tidak hanya profesi perawat yang membutuhkan UU ini tetapi calon profesi perawat juga harus mengetahui isi dari UUK agar dimasa mendatang bisa menjadi perawat yang taat akan aturan serta menjalankan hak dan kewajibannya sebagai seorang perawat.

Rumah sakit adalah bagian penting dari suatu sistem kesehatan, karena rumah sakit menyediakan pelayanan kuratif kompleks, pelayanan gawat darurat, berfungsi sebagai pusat rujukan dan merupakan pusat alih pengetahuan dan keahlian teknologi. Dalam meningkatkan kepuasan pemakai jasa, rumah sakit harus senantiasa meningkatkan mutu pelayanan sesuai dengan harapan pelanggan yang dapat dilakukan melalui peningkatan kualitas kinerja (Zahriany, 2009).

Prawirosentono (2010) menyatakan bahwa kinerja merupakan hasil karya yang dapat dicapai seseorang atau kelompok dalam rangka upaya mencapai tujuan organisasi sesuai dengan wewenang dan tanggung jawab masing-masing dalam rangka upaya mencapai tujuan organisasi bersangkutan secara legal, tidak melanggar hukum dan sesuai dengan moral dan etika. Kinerja perawat yang kurang dapat disebabkan karena adanya unsur dari luar diri tenaga perawat yang mempengaruhi psikologis sehingga menurunkan semangat kerja. Aspek yang berasal dari luar ini mencakup hubungan interpersonal dengan teman sejawat di tempat kerja, adanya konflik internal keorganisasiaan rumah sakit, kurangnya aspek motorik dari rumah sakit dalam rangka pemberian motivasi kepada tenaga perawat sehingga dapat melaksanakan tindakan asuhan keperawatan yang lebih berkualitas dan menjawab tuntutan masyarakat akan kebutuhan pelayanan (Andi, 2017).

Hasil survey awal peneliti pada Rumah Sakit TK.IV IM 07.01 Lhokseumawe terhadap kinerja perawat ditinjau dari aspek kedisiplinan masih banyak perawat yang belum dapat mentaati peraturan yang berlaku dalam institusi rumah sakit, seperti pelanggaran terhadap jadwal kerja, datang dan pulang tidak pada waktu yang telah ditentukan. Sehubungan dengan keadaan di atas, maka peneliti tertarik mengkaji secara ilmiah tentang Kinerja Perawat Pada Rumah Sakit TK.IV IM 07.01 Lhokseumawe ditinjau dari undang-undang keperawatan No. 38 Tahun 2014 dengan tujuan ingin menggali lebih dalam hal tersebut sehingga akan diperoleh input yang kelak akan membantu peningkatan mutu pelayanan rumah sakit, terutama pada peningkatan kinerja perawat sesuai dengan Undang-Undang No. 38 Tahun 2014 di masa yang akan datang.

\section{METODE PENELITIAN}

Penelitian ini menggunakan pendekatan kuantitatif, dengan Populasi dalam penelitian ini adalah pegawai yang menjadi populasi dalam penelitian ini adalah seluruh pada Rumah Sakit TK.IV IM 07.01 Lhokseumawe sebanyak 143 perawat, populasi pada penelitian ini adalah semua perawat yang 
berstatus sebagai perawat Tenaga Suka Rela (TKS) yang bertugas memberikan pelayanan keperawatan di Rumah Sakit TK.IV IM 07.01 Lhokseumawe. Sampel yang digunakan sebanyak 75 perawat. instrument yang digunakan dalam penelitian ini adalah kuesioner. Metode penelitian yang digunakan untuk mengetahui bagaimana pengaruh antar variabel prediktor (independen/ekogen) dan variabel terikat (dependen/endogen) digunakan analisis model multiple regression analisys (analisis regresi berganda).

\section{HASIL PENELITIAN}

Analisis regresi linier berganda digunakan dalam penelitian ini dengan tujuan untuk membuktikan hipotesis mengenai pengaruh bebas yaitu variabel motivasi kerja dan disiplin kerja secara parsial maupun secara bersama-sama terhadap kinerja perawat pada Rumah Sakit TK.IV IM 07.01 Lhokseumawe. berikut ini:

\section{Hasil Analisis Regresi Linier Berganda}

\begin{tabular}{|c|c|c|c|c|}
\hline \multirow[b]{2}{*}{ Model } & \multicolumn{2}{|c|}{$\begin{array}{cc} & \text { Standa } \\
\text { Unstandard } & \text { rdized } \\
\text { ized } & \text { Coeffic } \\
\text { Coefficients } & \text { ients } \\
\end{array}$} & \multirow[b]{2}{*}{$t$} & \multirow[b]{2}{*}{ Sig. } \\
\hline & $\begin{array}{cc} & \text { Std. } \\
B & \text { Error }\end{array}$ & Beta & & \\
\hline 1 (Constant) & 1.1671 .866 & & 0.626 & 0.534 \\
\hline $\begin{array}{l}\text { Motivasi } \\
\text { Kerja } \\
(\mathrm{MK}) \\
\end{array}$ & 0.1630 .074 & 0.226 & 2.214 & 0.030 \\
\hline $\begin{array}{l}\text { Kepemim } \\
\text { pinan } \\
(\mathrm{KP}) \\
\end{array}$ & 0.1720 .066 & 0.262 & 2.597 & 0.011 \\
\hline $\begin{array}{l}\text { Fasilitas } \\
\text { Kerja } \\
(\mathrm{FK})\end{array}$ & 0.0940 .070 & 0.141 & 1.351 & 0.181 \\
\hline $\begin{array}{l}\text { Pelatihan } \\
\text { (PL) }\end{array}$ & 0.1510 .073 & 0.209 & 2.077 & 0.042 \\
\hline $\begin{array}{l}\text { Imbalan } \\
\text { \& Jasa } \\
\text { (IJ) }\end{array}$ & 0.1390 .068 & 0.206 & 2.041 & 0.045 \\
\hline
\end{tabular}

a. Dependent Variable: Kinerja Perawat

Berdasarkan Tabel diatas, model persamaan regresi yang dapat dituliskan dari hasil Unstandardized coefficients tersebut, dengan analisis persamaan regresinya sebagai berikut:

\section{$\mathrm{Y}=$}

$1,167+0,163 X_{1}+0,172 X_{2}+0,094 X_{3}+0,151 X_{4}+$ $\mathbf{0 , 1 3 9}_{5}+\mathrm{e}$

Pada persamaan regresi tersebut dapat dilihat bahwa pembagian kerja dan budaya kerja mampu mempengaruhi kinerja pegawai. Dapat menjelaskan sebagai berikut:

1. Nilai konstanta (a) sebesar 1,167 artinya bahwa jika motivasi kerja, kepemimpinan, fasilitas kerja, pelatihan dan imbalan dan jasa dianggap konstan, maka nilai rata-rata kinerja pegawai sebesar 1,167.

2. Nilai koefisien $b_{1}$ (motivasi kerja) sebesar 0,163 bernilai positif, berarti pengaruh variabel motivasi kerja searah dengan kinerja perawat pada Rumah Sakit TK.IV IM 07.01 Lhokseumawe, hal ini menunjukkan bahwa variabel motivasi kerja mempunyai pengaruh positif dan signifikan terhadap kinerja perawat pada Rumah Sakit TK.IV IM 07.01 Lhokseumawe.

3. Nilai koefisien $b_{2}$ (kepemimpinan) sebesar 0,172 bernilai positif, berarti pengaruh variabel kepemimpinan searah dengan kinerja perawat pada Rumah Sakit TK.IV IM 07.01 Lhokseumawe, hal ini menunjukkan bahwa variabel kepemimpinan mempunyai pengaruh positif dan signifikan terhadap kinerja perawat pada Rumah Sakit TK.IV IM 07.01 Lhokseumawe.

4. Nilai koefisien $b_{3}$ (fasilitas kerja) sebesar 0,094 bernilai positif, berarti pengaruh variabel vasilitas kerja searah dengan kinerja perawat pada Rumah Sakit TK.IV IM 07.01 Lhokseumawe, hal ini menunjukkan bahwa variabel fasilitas kerja mempunyai pengaruh positif dan signifikan terhadap kinerja perawat pada Rumah Sakit TK.IV IM 07.01 Lhokseumawe. 
Nilai koefisien $b_{4}$ (pelatihan) sebesar 0,151 bernilai positif, berarti pengaruh variabel pelatihan searah dengan kinerja perawat pada Rumah Sakit TK.IV IM 07.01 Lhokseumawe, hal ini menunjukkan bahwa variabel pelatihan mempunyai pengaruh positif dan signifikan terhadap kinerja perawat pada Rumah Sakit TK.IV IM 07.01 Lhokseumawe. Nilai koefisien $b_{5}$ (imbalan dan jasa) sebesar 0,139 bernilai positif, berarti pengaruh variabel imbalan dan jasa searah dengan kinerja perawat pada Rumah Sakit TK.IV IM 07.01 Lhokseumawe, hal ini menunjukkan bahwa variabel imbalan dan jasa mempunyai pengaruh positif dan signifikan terhadap kinerja perawat pada $\begin{array}{llll}\text { Rumah Sakit TK.IV IM } 07.01 & \end{array}$ Lhokseumawe.

\section{PEMBAHASAN}

Berdasarkan hasil pengujian hipotesis terbukti motivasi kerja berpengaruh positif dan signifikan terhadap kinerja perawat Rumah Sakit TK.IV IM 07.01 Lhokseumawe, hasil analisis membuktikan bahwa motivasi kerja mempunyai nilai Sig. 0.030 yang dihasilkan dari model analisis regresi berganda adalah sebesar $0,030<0,05$ sehingga dapat dinyatakan bahwa adanya pengaruh positif dan signifikan motivasi kerja terhadap kinerja perawat Rumah Sakit TK.IV IM 07.01 Lhokseumawe.

Hal ini berarti bahwa semakin tinggi motivasi kerja, baik pertasi perawat, pengaruh positif dan pengawasan kerja, hasil penelitian ini didukung oleh penelitian Lumbanraja (2007), Robbin (2011) dan Siahaan (2017), menyimpulkan bahwa motivasi kerja secara parsial berpengaruh terhadap kinerja. Kemudian hasil penelitian Bangun (2012) dan Noor (2014) menyatakan bahwa terdapat hubungan dan pengaruh motivasi kerja dengan kinerja.

Kepemimpinan berpengaruh positif dan signifikan terhadap kinerja perawat Rumah Sakit TK.IV IM 07.01 Lhokseumawe, hasil analisis membuktikan bahwa kepemimpinan mempunyai nilai Sig.
0.011 yang dihasilkan dari model analisis regresi berganda adalah sebesar $0,011<0,05$ sehingga dapat dinyatakan bahwa adanya pengaruh positif dan signifikan kepemimpinan terhadap kinerja perawat $\begin{array}{llll}\text { Rumah Sakit TK.IV IM } 07.01 & \end{array}$ Lhokseumawe.

Semakin tinggi peran kepemimpinan, sikap toleransi atasan, integritad dan kekuasan yang dimiliki atasan dapat meningkatkan kinerja perawat, hasil penelitian ini didukung oleh penelitian Lumbanraja (2007), Robbin (2011), Marbawi (2018) dan Siahaan (2017), menyimpulkan bahwa kepemimpinan secara parsial berpengaruh terhadap kinerja pegawai. Kemudian hasil penelitian Luthans (2011) dan Noor (2014) menyatakan bahwa terdapat hubungan dan pengaruh kepemimpinan dengan kinerja pegawai pada sebuah organisasi.

Hasil pengujian hipotesis membuktikan fasilitas kerja tidak berpengaruh dan signifikan terhadap kinerja perawat Rumah Sakit TK.IV IM 07.01 Lhokseumawe, hasil analisis membuktikan bahwa fasilitas kerja pada rumah sakit mempunyai nilai Sig. 1.181 yang dihasilkan dari model analisi regresi berganda adalah sebesar $1,181>0,05$ sehingga dapat dinyatakanbahwa adanya tidak terdapat pengaruh fasilitas kerja terhadap kinerja perawat Rumah Sakit TK.IV IM 07.01 Lhokseumawe.

Fasilitas yang tersedia pada Rumah Sakit TK.IV IM 07.01 Lhokseumawe, kepemilikan komputer, gedung dan lapangan parkir pada Rumah Sakit TK.IV IM 07.01 Lhokseumaw tidak dapat meningkatkan kinerja pegawai, hasil penelitian ini tidak didukung oleh penelitian Hasibuan (2010), Robbin (2011) dan Rivai (2014), menyimpulkan bahwa fasilitas kerja secara parsial berpengaruh terhadap kinerja.

Pengujian hipotesis menunjukan pelatihan berpengaruh positif dan signifikan terhadap kinerja perawat Rumah Sakit TK.IV IM 07.01 Lhokseumawe, hasil analisis membuktikan bahwa pelatihan mempunyai nilai Sig. 0.042 yang dihasilkan dari model analisi regresi berganda adalah sebesar 0,042 
$<$ 0,05 sehingga dapat dinyatakan bahwa adanya pengaruh positif dan signifikan pelatihan terhadap kinerja perawat Rumah Sakit TK.IV IM 07.01 Lhokseumawe. Hal ini berarti bahwa semakin baik program pelatihan, baik pertasi perawat, pengaruh positif dan pengawasanmateri pelatihan, instruktur dan fasilitas pelatihan kerja perawat pada Rumah Sakit TK.IV IM 07.01 Lhokseumawe, hasil penelitian ini didukung oleh penelitian Rivai (2014), Robbin (2011) dan Sikumbang (2015), menyimpulkan bahwa pelatihan secara parsial berpengaruh terhadap kinerja. Kemudian hasil penelitian Bangun (2012) dan Handoko (2010) menyatakan bahwa terdapat hubungan dan pengaruh pelatihan dengan kinerja pegawai.

$$
\text { Berdasarkan hasil pengujian }
$$

hipotesis, terbukti imbalan dan jasa berpengaruh positif dan signifikan terhadap kinerja perawat Rumah Sakit TK.IV IM 07.01 Lhokseumawe, hasil analisis membuktikan bahwa motivasi kerja mempunyai nilai Sig. 0.045 yang dihasilkan dari model analisi regresi berganda adalah sebesar $0,045<0,05$ sehingga dapat dinyatakan bahwa adanya pengaruh positif dan signifikan imbalan dan jasa terhadap kinerja perawat Rumah Sakit TK.IV IM 07.01 Lhokseumawe.

Hal ini berarti bahwa semakin baik sistim imbalan dan jasa, baik gaji, insentif dan bonus untuk perawat pada Rumah Sakit TK.IV IM 07.01 Lhokseumawe maka semakin baik kinerjanya dalam bekerja, hasil penelitian ini didukung oleh penelitian bangun (2012), Robbin (2011) dan Rivai (2014), menyimpulkan bahwa kompensani berupa imbalan secara parsial berpengaruh terhadap kinerja. Kemudian hasil penelitian Siahaan (2017) dan Hasibuan (2010) menyatakan bahwa terdapat hubungan dan pengaruh kompensasi berupa imbalan dengan kinerja.

\section{KESIMPULAN}

Berdasarkan hasil penelitian terdapat pengaruh positif dan signifikan motivasi kerja, kepemimpinan, pelatihan, imbalan dan jasa terhadap kinerja perawat. Kepemimpian merupakan faktor yang sangat dominan dalam rangka meningkatkan kinerja perawat.

\section{SARAN}

Fasilitas kerja tidak berpengaruh terhadap kinerja perawat, hal ini harus menjadi perhatian pimpinan untuk meningkatkan fasilitas lengkap dan lingkungan kerja yang aman nyaman sehingga memberikan kepuasan dan akan meningkatkan kinerjanya.

\section{REFERENSI}

Andi, (2010). Faktor-Faktor Yang Berhubungan Dengan Kinerja Perawat di RS Dr. achmad Mochtar Bukit Tinggi. Program Studi Ilmu Keperawatan Fakultas Kedokteran Universitas Hasanuddin.

Bangun, Wilson., (2012). Manajemen Sumber Daya Manusia, Penerbit Erlangga, Jakarta.

Handoko, 2011. Manajemen Personalia dan sumber daya manusia. Yogyakarta. BPFE.

Lumbanraja, Prihatin., (2007). Desertasi: Pengaruh Kateristik Individu, Gaya Kepemimpinan dan Budaya Organisasi Terhadap Kepuasan Kerja dan Komitmen Organisasi, Program Pascasarjana, Universitas Brawijaya Malang.

Luthans, Fred., (2011). Organizational Behavior, Tweltf Edition, McGraw-Hill Companies Inc. New York.

Marbawi, (2018). Pengaruh Karakteristik Individu, Budaya Organisasi Dan Kepemimpinan Transformasional Terhadap Kepuasan Kerja Dan Kinerja Karyawan Pada Bank Aceh, Disertasi Universitas Sumatera Utara, Medan.

Noor, Juliansyah., (2013). "Penelitian Manajemen" Tinjauan Filosofis dan Praktis Edisi Pertama, Prenadamedia Group, Jakarta.

Prapuspa, (2013). Analisis Kinerja Perawat Dalam Pengendalian Infeksi Nosokomial Di IRNA I RSUP DR. 
Sardjito.Jurnal Universitas Gadjah Mada.

Prawirosentono, 2010. Manajemen Sumber Daya Manusia: Kebijakan Kinerja Karyawan. Yogyakarta: BPFE.

Rivai, Veithzal dan E.J. Sagala., (2014). Manajemen Sumber Daya Manusia untuk Perusahaan: dari Teori Ke Praktik, Edisi Pertama, Penerbit PT. Raja Grafindo Persada, Jakarta

Robbins, Stephen, P dan Timothy A. Judge., (2013). Organizational Behavior, Edisi $15^{\text {th }}$. Prentice Hall International Inc, New Jersey.

Siahaan, Elisabet., (2017). Anteseden Kinerja Karyawan dan Pengaruhnya Terhadap Kepuasan Kerja Karyawan: Studi Berdasarkan Perspektif Jender Pada Sektor Jasa Perbankan di Wilayah DKI Jakarta, Universitas Brawijaya Program Pascasarjana, Malang.

Zahriany, (2009). Hubungan Karakteristik Individudan Psikologis terhadap Kinerja Perawat dalam Kelengkapan Rekam Medis di Ruang Rawat Inap Rumah Sakit Umum Dr, Pringadi Medan. Tesis. Program Studi AKK USU, Medan 